unconnected facts. A strange example is the treatment of the equivalence of mass and energy, attributed to Einstein and discussed in some detail, but in no way related to the subsequent chapter on the special theory of relativity. But, having grumbled a little, let me say what a useful book it is. It crams an enormous amount into 683 double-columned pages, with line drawings or photographs of equipment on every page. Because the student is assumed weak in mathematics, most results quoted

\section{Remote sensing of the environment}

\section{R.N. Colwell}

Introduction to Remote Sensing of the Environment. Edited by Benjamin F. Richason Jr. Pp.496. (Kendal/Hunt: Dubuque, Iowa, 1978.) \$27.00. Laboratory Manual for Introduction to Remote Sensing of the Environment. Edited by Benjamin F. Richason Jr. Pp.237. (Kendal/Hunt: Dubuque, Iowa, 1978.) $\$ 8.95$.

THESE two books are companion volumes prepared by 24 contributors under sponsorship of the National Council for Geographic Education and published in the Council's Pacesetter Series.

The first chapter of the textbook provides a stage-setting overview. The second chapter describes the nature of electromagnetic energy and of basic matter/energy relationships. The next eight chapters describe various remote sensing devices and aerospace image acquisition systems; included are illustrations of the interpretation of blackand-white, colour, and colour infrared photographs, and of imagery acquired by thermal infrared scanners, multispectral scanners and microwave sensors. The next nine chapters deal with specific remote sensing applications including the analysis of landforms, rural cultural landscapes, agriculture, forestry, urban and industrial areas and weather phenomena; cartographic and regional planning applications are also included. The concluding chapter constitutes both a summary and a look to the future. The book's four appendices list sources from which remote sensing imagery and data tapes can be obtained, provide reference materials for beginning students, and present colour reproductions of various types of imagery. They are followed by biographical information about the contributing authors and a brief subject index. A much needed glossary is not included. The laboratory manual closely parallels the textbook, with appropriate emphasis on applications.

The scope of these two volumes is are backed up by generous experimental even anecdotal - detail, as well as some basic mathematical exposition. Physics for its own sake gets little space - particle physics hardly figures at all - but there is a chapter on electric shocks and electrical safety which taught me a geat deal that I should have known before; and the chapters on optics and hydrodynamics are sensible and detailed. There are twenty or thirty simple problems at the end of each chapter, with answers to the odd numbers at the back. The bibliography for each chapter is eclectic - not many specialised textbooks but a range of historical material, memoirs of scientists and Scientific American articles. There are appendices on basic mathematics, physical constants and units, "well known functions", and problem-solving with calculators.

David J. Miller is a Lecturer in the Department of Physics and Astronomy, University College London, UK. excellent and the concept of multiple authorship is commendable. The quality with which the image examples are reproduced ranges from good to excellent and most of the writing is highly articulate. Closer study of the textbook suggests, however, that its chapters comprise more a compendium of separate treatises than a well integrated introduction to remote sensing. One manifestation of this is a lack of standardisation of terminology. For example, is "remote sensing" (the most fundamental of terms) limited to the mere "imaging of features", as defined in the Preface? Does it include the obtaining of digital records, as implied later in the text? In addition to data acquisition, is data analysis encompassed by this term? If so, does the analysis encompass work done not only by humans but also by machines? With respect to balance: (1) symptomatically, the chapter on agriculture planning is given roughly four times this emphasis in both respects; (2) of the 24 contributors, no less than 20 appear to be geographers; (3) more than half of the 24 colour plates pertain to features in the Great Lakes area; and (4) while the captions for a few of these colour plates are quite complete and are well crossreferenced to the two books, the captions for others indicate only the image type and/or geographic location.

Superficially, the laboratory manual is

very impressive, well illustrated and well matched to the supporting textbook. On a closer look, several of the exercises appear decidedly superficial. Also, the limited use of aerial photo stereograms gives the erroneous impression that threedimensional perception and interpretation are of little importance.

There are notable strengths to offset these deficiencies. For example, Chapter 2 provides a masterful disclosure of some very important but highly complex material at a level that can be readily comprehended by most beginning students. Similarly, Chapter 16, dealing with regional planning, is clearly expressed, reasonably comprehensive, well balanced and well illustrated.

In summary, these two books represent a commendable effort to satisfy a longstanding need, that of providing the beginning student with a reasonably comprehensive remote sensing textbook and laboratory manual that might be digested in a single four-or five-unit course at the college or university level. A more carefully edited and better balanced second edition would far better satisfy this need.

R.N. Colwell teaches courses in photo interpretation and remote sensing at the University of California, Davis, California.

\section{Practical organic chemistry}

\section{J.E. Girard}

Practical Organic Chemistry: A Basic Course. By V.V. Nekrasov. Pp.410. (MIR Publishers: Moscow, 1978.) \$7.80.

THIS fifth edition of a popular Russian text has been translated into English by Alexandar Rosinkin. What is not evident from the title of this book is that it is a laboratory text for students at vocational or technical school or for non-chemistry university students. As the author states in the introduction, this text is intended to be "only a practical manual, and it cannot rival the textbook of organic chemistry.
The theory is given in a limited scope".

For the most part, the chapters are arranged according to functional groups. Within chapters are experiments dealing with qualitative organic analysis and simple synthesis. The latter chapters deal with polymer reactions, precipitation and denaturing proteins, hydrolysis of fats, preparation of mustard oils and reactions of carbohydrates.

Although this is a very thorough treatment, it is somewhat out of date. The translator has unfortunately chosen to use words or phrases that are not commonly used. This may cause beginning students undue confusion.

J.E. Girard is an Associate Professor in the Department of Chemistry, College of Arts and Science, the American University, Washington DC. 